The University of Southern Mississippi The Aquila Digital Community

Faculty Publications

$11-6-2017$

\title{
The Role of Feature-Based Discrimination In Driving Health Disparities Among Black Americans
}

Randl B. Dent

Virginia Commonwealth University

Nao Hagiwara

Virginia Commonwealth University, nhagiwara@vcu.edu

Elena V. Stepanova

University of Southern Mississippi, elena.stepanova@usm.edu

Tiffany L. Green

Virginia Commonwealth University

Follow this and additional works at: https://aquila.usm.edu/fac_pubs

Part of the Psychology Commons

\section{Recommended Citation}

Dent, R. B., Hagiwara, N., Stepanova, E. V., Green, T. L. (2017). The Role of Feature-Based Discrimination In Driving Health Disparities Among Black Americans. Ethnicity \& Health.

Available at: https://aquila.usm.edu/fac_pubs/16568 
The role of feature-based discrimination in driving health disparities among Black Americans

Randl B. Dent, B.A ${ }^{1}$, Nao Hagiwara, Ph.D. ${ }^{2}$, Elena V. Stepanova, Ph.D. ${ }^{3}$, \& Tiffany Green, Ph.D. ${ }^{4}$

1. Department of Psychology, Virginia Commonwealth University, 806 West Franklin Street, Richmond, VA 23284, USA, dentrb@ vcu.edu

2. Department of Psychology, Virginia Commonwealth University, 808 West Franklin Street, Richmond, VA 23284, USA, nhagiwara@vcu.edu

3. Department of Psychology, The University of Southern Mississippi, 118 College Drive \#5025, Hattiesburg, MS 39406, elena.stepanova@usm.edu

4. Department of Health Behavior and Policy, Virginia Commonwealth University, P.O. Box: 980430, Richmond, VA 23219, tiffany.green@vcuhealth.org

Author Note

Please address correspondence to Nao Hagiwara, Department of Psychology, Virginia Commonwealth University, 806 West Franklin Street, Box 842018, Richmond, VA 23284, USA, Phone: 804-828-6822, Fax: (804) 828-2237; Email: nhagiwara@vcu.edu. 


\begin{abstract}
Objective: A growing body of research finds that darker skin tone is often associated with poorer physical and mental health in Blacks. However, the psychosocial mechanisms underlying the skin tone-health link remain elusive. The present study seeks to address this knowledge gap by investigating the direct and indirect (through perceived discrimination, socioeconomic status, and self-esteem) effects of skin tone on self-reported physical and mental health.

Design: An urban sample of 130 Blacks aged 35 and above completed a self-administered computerized survey as a part of larger cross-sectional study.

Results: Self-esteem played a particularly important role in mediating the associations between skin tone and self-reported physical and mental health. This suggests that self-esteem could be a point of intervention to help Blacks with darker skin tone achieve better health.

Conclusion: The present study highlights the important role feature-based discrimination plays in determining mental and physical health outcomes among Blacks.
\end{abstract}

Keywords: skin tone; perceived discrimination; socioeconomic status; self-esteem; health disparities 


\section{Introduction}

A growing body of research has documented associations between darker skin tone and poorer physical and mental health in Blacks (Dressler 1991; Harburg et al. 1978; Keil et al. 1981; Sweet et al. 2007; Williams and Williams-Morris 2000; for exceptions see Borrell et al. 2006; Keith et al. 2010). Blacks with darker, as opposed to lighter, skin tone are more likely to be diagnosed with hypertension (Monk 2015) and to have higher blood pressure, greater body mass index, and greater smoking prevalence (Armstead et al. 2013). These findings are consistent with recent social psychology evidence demonstrating that Blacks experience unfair treatment based on both racial group membership (i.e., category-based discrimination) and the strength of physical features that signals African ancestry, including skin and eye colors, nose width, lip thickness, and (i.e., feature-based discrimination; Blair et al. 2002; Livingston and Brewer 2002). However, the psychosocial mechanisms underlying the skin tone-health link remain elusive. Understanding these mechanisms are crucial for developing effective interventions designed to reduce the negative health consequences of feature-based discrimination. To address this knowledge gap, we investigated the direct and indirect effects of skin tone on self-reported physical and mental health in a cross-sectional study of Blacks aged 35 and above. Specifically, we investigated three psychosocial mechanisms that may underlie the link between skin tone and health: perceived discrimination, socioeconomic status (SES), and self-esteem.

\section{Potential Psychosocial Factors Mediating the Skin Tone-Health Link}

Evidence from the social psychology, sociology, and applied health literatures suggests that perceived discrimination, SES, and self-esteem might mediate the relationship between skin tone and health. First, darker skin tone is strongly associated with greater perceived discrimination (Keith and Herring 1991; Klonoff and Landrine 2000; Uzogara et al. 2013; Monk 
2015). For example, Klonoff and Landrine (2000) found Blacks with darker skin tone were 11 times more likely to experience racial discrimination than those with lighter skin tone. Darker skin tone also appeared to exacerbate the effects of discrimination: Blacks with darker skin tone rated discriminatory incidents as more stressful than their counterparts with lighter skin tone. In turn, higher levels of perceived discrimination can adversely impact physical and mental health (Abramson, Hashemi, and Sánchez-Jankowski 2015; Pascoe and Smart Richman 2009). Previous research has found that the experience of racial discrimination is associated with biological markers of stress, such as cortisol levels (Richman and Jonassaint 2008), allostatic load (Brody et al. 2014), and various markers of inflammation (Massey 2004; Cooper et al. 2009). Additionally, perceived discrimination has been associated with maladaptive coping behaviors, such as tobacco use (Bennett et al. 2005) and alcohol use (Martin, Tuch, and Roman 2003; Borrell et al. 2007). These biological markers of stress and maladaptive coping behaviors may put Black individuals at particular risk for additional physical health and mental health problems. Taken together, given that Blacks with darker skin tone are exposed to greater levels of discrimination, they in turn might be at heightened risk for adverse health outcomes.

SES is another plausible link between skin tone and health. Among Blacks, lighter skin is associated with greater educational attainment, higher income and wages, and better marriage quality (Allen, Telles, and Hunter 2000; Branigan et al. 2013; Hughes and Hertel 1990; Hamilton, Goldsmith, and Darity 2009). Low SES is a source of chronic stress (Franks, Gold, and Fiscella 2003; Gruenewald et al. 2012; Lipowicz, Szklarska, and Malina 2014; Upchurch et al. 2015) and can lead to maladaptive coping behaviors, such as substance use (Daniel et al. 2009), adversely impacting individuals' physical and mental health. Low SES can also result in less access to quality healthcare (Altschuler, Somkin, and Adler 2004; Becker and Newsom 
2003; Castor et al. 2006). For example, in a randomized audit study of physicians' offices, Olah, Gaisaino, and Hwang (2013) found that potential patients were more likely to be offered an appointment when they presented themselves as having higher socioeconomic status (SES). Others have found that low-income patients were less likely to receive proper treatment and had an overall worse survival rate, independent of race (Bristow et al. 2013). Thus, it is incredibly important to consider SES as mechanism by which skin tone may affect physical and mental health. In sum, prior research suggests that Blacks with darker skin tone tend to have low SES, which further may result in an increased risk for poor health outcomes.

Finally, darker skin tone is also generally associated with lower self-esteem among Blacks (Coard, Breland, and Raskin 2001; see exceptions for Harvey et al. 2005). For example, Thompson and Keith (2001) found Black women with darker, as opposed to lighter, skin tone had lower self-esteem. Robinson and Ward (1995) found a similar association in both male and female adolescents. In a separate line of research, self-esteem has been found to be associated with self-reported physical and mental health (Antonucci, Peggs, and Marquez 1989; Carroll and Buhrow 1994; Orth, Robins, and Widaman 2012). For example, Trzesniewski et al. (2006) report that lower self-esteem in adolescence predicted more physical health problems in early adulthood. High self-esteem contributes to psychological resilience, allowing individuals to cope with and quickly recover from stress (Chan, Lai, and Wong 2006; Harris et al. 2016; Yi et al. 2008). High self-esteem can also prevent individuals from engaging in risky health behaviors, such as binge-drinking and unprotected sex (Danielson et al. 2014; Gullette and Lyons 2006). Given that Blacks with darker skin tone are likely to have low levels of self-esteem, they further might be at heightened risk for poor health outcomes. Taken together, based on the extant literature, we hypothesized that darker skin tone would be associated with poorer self-reported 
physical and mental health in Blacks and that the association would be mediated by perceived discrimination, SES, and self-esteem independently.

We also explored gender as a potential moderator of the mediated relationships between skin tone and health because gender effects have been reported in all three proposed mediators. Some research has shown that men and women are affected differently by perceived discrimination, such that women, but not men, experience poorer psychological well-being after experiencing discrimination based on their gender (Schmitt, Branscombe, Kobrynowicz, \& Owen, 2002). Additionally, SES also differs by gender, such that women tend to have lower SES than men in geenral (U.S Bureaus of Labor Statistics 2010). Finally, prior research provides strong evidence that men generally have higher self-esteem than women (Kling et al. 1999; Sprecher, Brooks, and Avogo 2013). Furthermore, there is evidence that the nature of the association between skin tone and self-esteem may differ between genders. Specifically, it has been shown that lighter skin tone is associated with higher self-esteem in Black women, but not in Black men (Robinson \& Wade, 1995; Thompson \& Keith, 2001). In sum, findings from prior research highlight gender as a potentially important factor that may moderate the association between skin tone and health.

\section{Method}

\section{Participants}

A sample of 130 self-identified Black adults $(56.2 \%$ women, age $M=49.21, S D=8.40)$ were recruited through flyers and purposive referral sampling in the Richmond, Virginia metropolitan area based on the following eligibility criteria: (1) was 35 years of age or older (in order to be able to capture enough variability in health status); (2) self-identified as Black/African American; (3) was able to visit the study lab for approximately one hour; (4) had a 
permanent address and personal phone number. Twelve participants were excluded from all analyses because they either indicated their race as Black/African American during the screening but not during the laboratory session $(n=9)$ or did not have the skin tone readings $(n=3)$. Finally, three participants either reported their age to be less than $35(n=2)$ or did not report their age $(n=1)$. The results from the analyses with and without those three participants were the same; thus, the present study reports the findings with those three participants. Taken together, our final analysis sample consisted of 118 cases $(57.6 \%$ women, age $M=49.02, S D=8.62)$.

\section{Procedure}

Up to two participants were scheduled for each laboratory session, which was conducted at two university centers by a Black research assistant. After signing the consent form, participants were first asked to undergo vital checks (i.e., blood pressure, heart rate, pain sensitivity and tolerance). Next, participants completed a computer-based survey that included a number of measures that are designed to assess their beliefs, attitudes, past experiences, and mental and physical health. Participants then underwent the same vital checks, and participant skin tone was assessed with a portable spectrometer. Finally, participant photographs were taken for subsequent analysis of their facial features. Participants were fully debriefed and compensated with $\$ 40$ for their participation. The study procedure was approved by the IRB at the authors' institution.

\section{Measures}

Skin tone. Four readings from participant face (i.e., both cheeks, forehead and chin) were obtained using a portable spectrophotometer (the HunterLab MiniScan EZ 4000L) and then averaged to obtain a single score. Luminosity value can range between 0 (a perfect black) to 100 (a perfect white), but the lowest and the highest scores in the current sample were 26.69 and 
57.90, respectively. Luminosity value was normally distributed with $M=40.61(S D=6.25)$ with skewness $=.40(S E=.22)$ and kurtosis $=-.50(S E=.44)$. Higher scores indicate lighter skin. A spectrophotometer was used to circumvent potential biases associated with self-reported and/or interviewer-rated skin tone (Saperstein and Penner 2010; Saperstein and Penner 2012). Additionally, luminosity readings were obtained from participant faces, as opposed to the underarm area (Borrell et al. 2006; Krieger, Sidney, and Coakley 1998; Sweet et al. 2007), because the previously reported associations between skin tone and our social determinants of interest (i.e., perceived discrimination, SES, and self-esteem) reflect social processes-how people perceive and react to others' skin tones - and people's first impressions are often made based on the others' most visible part of the body_face (Brewer 1988).

Self-reported physical and mental health. Using a modified version of the SF- 8 Health survey, participants reported their physical and mental health during the past 4 weeks (Ware Jr. et al. 2001). Following the standard guideline, the first four items (general health, physical functioning, role limitations due to physical problems; and pain) were averaged to compute physical health $(\alpha=.76)$, and the last four items (energy, social functioning, emotional wellbeing, and role limitation due to emotional problems) were averaged to compute mental health ( $\alpha$ $=.85)$. The scale ranged from 0 to 100 , with higher numbers indicating better health.

Perceived discrimination. Five items were selected from two measures (Branscombe, Schmitt, and Harvey 1999; Levin et al. 2002) to assess perceived discrimination. Example items include "I feel like I am discriminated against because of my race" and "I consider myself a person who is deprived of opportunities that available to others because of my race." The scale ranged from 1 (Strongly disagree) to 5 (Strongly agree), and higher numbers indicate greater perceived discrimination $(\alpha=.84)$. 
Socioeconomic status (SES). SES was assessed with household income from the previous year and highest education. Participants reported their income on a 5-point scale [(1) less than $\$ 20,000$; (2) $\$ 20,000$ to $\$ 39,999$; (3) $\$ 40,000$ to $\$ 59,999$; (4) $\$ 60,000$ to $\$ 89,999$; (5) more than $\$ 90,000]$ and their education on an 8-point scale [(1) None (I did not go to school); (2) I completed $8^{\text {th }}$ grade or less; (3) I completed $10^{\text {th }}$ grade or less; (4) I completed $12^{\text {th }}$ grade or less (did not graduate high school); (5) I graduated from high school; (6) I completed some college (did not graduate college); (7) I graduated from college; (8) I completed a post graduate degree]. In order to compute a composite SES score, first, $z$-scores were calculated for each income and education variable. Then, the $z$-score for income and the $z$-score for education were averaged to create the SES variable. Higher scores indicate higher SES.

Self-esteem. The 10-item Rosenberg (1965) self-esteem scale was used to assess participants" self-esteem $(\alpha=.76)$. Example items include "I feel that I am a person of worth at least on an equal basis with others" and "I feel that I have a number of good qualities." The scale ranged from 1 (strongly disagree) to 5 (Strongly disagree), with higher numbers indicating higher self-esteem.

\section{Analysis Plan}

The correlations indicated that participant age was significantly associated with their mental health $(r=.21, p=.03)$, but not physical health $(r=.08, p=.42)$. Thus, age was included in all analyses as a covariate. However, it should be noted that the overall results were the same for the analyses with and without age as a covariate. We conducted two separate tests of a parallel multiple mediator model using PROCESS (Hayes 2013): one for predicting physical health and another for predicting mental health. Specifically, we tested all three potential mediators in one model (i.e., Model 4 in PROCESS) with $N=5,000$ resamples. Skin tone, 
perceived discrimination, and self-esteem were grand-mean-centered. In each analysis, skin tone was entered as an independent variable, and perceived discrimination, SES, and self-esteem were entered as mediators. Direct and indirect effects were estimated even when a total effect did not reach statistical significance (Cerin and MacKinnon 2009; Hayes 2009). To explore whether gender would moderate the hypothesized mediated relationship between skin tone and health, the same specifications noted above was used with two exceptions: (1) we used Model 8 in PROCESS, and (2) gender (women $=0$, men $=1)$ was included as a moderator.

\section{Results}

Examinations of skewness, kurtosis, and distribution figured indicated that all variables were normally distributed. Table 1 presents the basic descriptive statistics. There was no evidence of gender difference in income $\left[\chi^{2}(4)=1.38, p=.85\right.$ with categories, $t(116)=1.09$, $S E=.18, p=.28$ with $z$-scores]. However, there was a statistically significant difference in education, such than women had higher education than men $\left[\chi^{2}(6)=18.29, p=.006\right.$ with categories, $t(116)=3.38, S E=.18, p<.0001$ with z-scores].

Consistent with our prediction, Blacks with darker skin tone reported poorer mental health than Blacks with lighter skin tone $(r=.21, p=.02 ; C I=.03, .38)$. We also found an association between darker skin tone and poorer physical health, though it did not reach the statistical significance $(r=.16, p=.095 ; C I=-.02, .33)$. Additionally, consistent with prior research, skin tone was significantly negatively associated with perceived discrimination $(r=-$ $.23, p=.01 ; C I=-.05, .39)$ : Blacks with lighter skin tone reported less perceived discrimination than those with darker skin tone. Skin tone was also associated positively with both SES $(r=.36$, $p<.0001 ; C I=.19, .51)$ and self-esteem $(r=.25, p=.007 ; C I=.07, .41)$. That is, Blacks with lighter skin tone reported higher levels of SES and self-esteem than those with darker skin tone. 


\section{[INSERT TABLE 2 HERE]}

Physical health. Although a correlation between skin tone and physical health did not reach the statistical significance, we proceeded to a mediation analysis because the recent research strongly suggests that the presence of the direct effect between independent and dependent variables is not a necessary step for conducting a mediation analysis and that what is more essential in a mediation analysis is examinations of the magnitude and significance of indirect effects (Hayes and Preacher, 2010; Rucker, Preacher, Tormala and Petty, 2011). As can be seen in Figure 1a, neither the total effect $\left(c^{\prime}: b=.54, S E=.32, p=.09, C I=-.63, .67\right)$ nor the direct effect of skin tone on physical health was significant $(c: b=.03, S E=.33, p=.93, C I=-$ $.62, .68)$. However, examinations of indirect effects revealed that the association between skin tone and physical health was significantly mediated by self-esteem $\left(a^{3 *} b^{3}: b=.35, S E=.16, C I\right.$ $=.10, .74)$. An examination of percent mediation suggests that self-esteem could account for $69 \%$ of the total effect, and the completely standardized indirect effect of self-esteem was $a b_{\mathrm{cs}}=$ $.11(C I=.04, .21)$. There was no evidence that the skin tone-physical health link was mediated by perceived discrimination $\left(a^{1 *} b^{1}: b=-.02, S E=.08, C I=-.19, .11\right)$ or $\operatorname{SES}\left(a^{2 *} b^{2}: b=.18, S E\right.$ $=.12, C I=-.02, .45$ ). Additionally, gender did not moderate the mediated relationship between skin tone and physical health: indices of moderated mediation for perceived discrimination $=$ $.001(S E=.13, C I=-.30, .27) ; \mathrm{SES}=-.13(S E=.15, C I=-.65, .02) ;$ and self-esteem $=-.03(S E$ $=.33, C I=-.66, .65)$. These findings suggest Blacks with lighter skin tone tended to have higher levels of self-esteem than Blacks with darker skin tone, regardless of gender, which was further associated with better physical health. Taken together, our hypothesis that darker skin tone was related to physical health through three mediators was partially supported.

[INSERT FIGURE 1 HERE] 
Mental health. Figure $1 \mathrm{~b}$ presents the results of mental health. The total effect was significant $\left(c^{\prime}: b=.71, S E=.31, p=.02, C I=.10,1.32\right)$. Although the direct effect of skin tone on mental health was not significant $(c: b=.07, S E=.31, p=.81, C I=-.54, .69)$, examinations of indirect effects revealed that the association between skin tone and mental health was significantly mediated by both perceived discrimination $\left(a^{1 *} b^{1}: b=.13, S E=.07, C I=.03,32\right)$ and self-esteem $\left(a^{3 *} b^{3}: b=.33, S E=.14, C I=.10, .68\right)$, independently. SES did not mediate the association $\left(a^{2 *} b^{2}: b=.09, S E=.11, C I=-.09, .34\right)$. An examination of percent mediation suggests that self-esteem and perceived discrimination could account for $52 \%$ and $19 \%$ of the total effect, respectively. The completely standardized indirect effect of self-esteem was $a b_{\mathrm{cs}}=$ $.11(C I=.04, .21)$, whereas that of perceived discrimination was $\mathrm{ab}_{\mathrm{cs}}=.04(C I=.1, .10)$.

Furthermore, there was no evidence that the mediated relationship between skin tone and mental health was moderated by gender: indices of moderated mediation for perceived discrimination $=$ $.27(S E=.21, C I=-.06, .83) ; \mathrm{SES}=-.08(S E=.12, C I=-.50, .05) ;$ and self-esteem $=-.03(S E=$ $.32, C I=-.62, .64)$. These results suggest Blacks with lighter skin tone experience better mental health than Blacks with darker skin tone because they experience less discrimination and have higher self-esteem. Again, our hypothesis that skin tone was related to mental health was partially supported.

\section{Discussion}

The overall goal of the present study was to investigate potential mechanisms through which skin tone affects physical and mental health. Consistent with our hypothesis and previous research, we found that Blacks with darker skin tone reported poorer mental health than Blacks with lighter skin tone. Blacks with darker skin tone also reported poorer physical health than Blacks with lighter skin tone, although this association did not reach statistical significance. Our 
analyses further revealed that Blacks with darker skin tone were likely than Blacks with lighter skin tone to report higher levels of perceived discrimination, have lower SES, and have lower self-esteem. These findings are consistent with prior social psychology and sociology research (Coard, Breland, and Raskin 2001; Hunter 2007; Monk 2015; Uzogara et al. 2013). Additionally, all three factors were significantly associated with physical and mental health (except for the association between perceived discrimination and physical health), which is consistent with the larger health disparities literature (Orth, Robins, and Widaman 2012; Pascoe and Smart Richman 2009; Quon and McGrath 2015).

Interestingly, our findings show that only self-esteem consistently mediated the associations between skin tone and self-reported physical and mental health. This skin tonehealth association through self-esteem was not moderated by gender. Puzzlingly, we failed to find a link between skin tone, perceived discrimination, and physical health. One potential explanation is that perceived discrimination might have long-run, rather than immediate, effects on physical health. For example, increased allostatic load, which has been found to be one major biological mechanism underlying the perceived discrimination-physical health link (Mays, Cochran, and Barnes 2007; Brody et al. 2014; Tomfohr, Pung, and Dimsdale 2016), may not manifest until decades of exposure (Hayman, Lucas, and Porcerelli 2014; Duru et al. 2012; Jackson et al. 2011). Another potential explanation is use of global health functioning. Items included in the measure do not enable researchers to effectively capture asymptomatic diseases, such as hypertension, diabetes, and some types of cancer. Finally, our relatively small sample size might have contributed to our finding that perceived discrimination was unrelated to physical health. With a larger sample, perceived discrimination might have been found to be a significant mediator for the skin tone-physical health link. 
Our analyses also revealed that SES was not a significant mediator between skin tone and health, when its effects were directly compared to perceived discrimination and self-esteem. One likely reason is the shared variance between SES and self-esteem. As can be seen in Table 2, SES was modestly associated with self-esteem. Thus, there might not have been enough variance left after controlling for self-esteem. Again, a small sample size may also explain the null finding.

We posit that self-esteem may better serve as a point of intervention than perceived discrimination to help Blacks with darker skin tone achieve better health for several reasons. First, the present findings have shown that only self-esteem mediated the associations between skin tone and both physical and mental health. Second, we recognize that intervening with perceived discrimination, which is another significant mediator of the skin tone-mental health link, is critical. However, reducing the actual occurrences of discrimination requires tremendous effort and time as discrimination is deep-rooted in U.S. history and culture-both category-based and feature-based discriminations are still pervasive even 152 years after slavery in the U.S. has officially ended. Thus, while the society addresses the system-wide discrimination, personallevel interventions designing to improve self-esteem should mitigate the deleterious effects of feature-based discrimination. Some may argue that if it is difficult to reduce the occurrences of discrimination, scholars may be able to intervene with individuals' perceptions of discrimination. However, it is not ethical to reduce individuals' perceptions of discrimination because inability to recognize injustices happening to them could result in little motivation to engage in social activism to promote social equity and justice. Third, prior research has shown that self-esteem is relatively malleable (Barrett, Webster, and Wallis 1999; Okeke-Adeyanju et al. 2014). In fact, there are already several interventions that have been found to be effect in improving 
individuals' self-esteem in general populations (Mruk 2006; Tirlea, Truby, and Haines 2016) as well as specifically within Black populations (Belgrave et al. 2000; Ghee, Walker, and Younger 1998). For example, social psychology research on self-affirmation has shown that a simple exercise that is designed to provide self-affirmation (e.g., identifying one's values and strengths) can improve self-esteem (Cohen and Sherman 2014; Fein and Spencer 1997; Tesser 2000). It has also shown that physical activity can increase self-esteem (Tremblay, Inman, and Willms 2000), suggesting that interventions that are designed to increase physical activities can not only improve health directly but also indirectly through increased self-esteem. Within Black communities, self-empowerment programs have been demonstrated to be effective in improving students' self-esteem, which is further associated with increased social and academic success (Day-Vines and Terriquez 2008; Tucker and Herman 2002). Clearly, the effectiveness of these interventions to improve self-esteem particularly among Black Americans with darker skin tone should be empirically tested in future research. However, these existing programs will greatly inform future intervention research. Finally, it has been shown that individuals with higher, as opposed to lower, self-esteem can cope better when facing discrimination (Umaña-Taylor et al. 2008; Wei et al. 2008; Feng and Xu 2015; Corning 2002). This suggests that interventions for self-esteem can also serve indirectly as interventions for perceived discrimination.

\section{Limitations and Future Directions}

One major limitation is that the study was conducted with a relatively small sample of Blacks living in Richmond, VA. As discussed earlier, the null association between perceived discrimination and physical health may become significant with a larger sample. Additionally, Richmond has a unique racial history as it was once the capital of the confederacy. Thus, 
whether the current findings can be generalized to Black populations elsewhere should be empirically tested.

Another limitation is that skin tone was assessed by obtaining luminosity readings only from faces. A few previous studies that have used spectrophotometers for skin tone assessment obtained luminosity readings from underarms to avoid the effects of sun exposure (Borrell et al. 2006; Krieger, Sidney, and Coakley 1998; Pershing et al. 2008; Sweet et al. 2007). It is unclear whether the current findings could be replicated with different methods of skin tone assessment. Future research should assess skin tone using multiple methods (e.g., self-report, interviewerrating, underarm luminosity reading, and face luminosity reading) and directly compare potential effects of these different measures.

Finally, the present study exclusively focused on potential psychosocial mechanisms underlying the association between skin tone and health in Black Americans. However, there are some evidence suggesting that there may be other pathways through which skin tone may impact health. For example, higher tissue retention rates of nicotine in individuals with darker skin tone (i.e., with higher melanin concentration) have been documented (King et al., 2009). This finding suggests that smoking could have more adverse impacts on individuals with darker skin tone than for those with lighter skin tone, even when the frequency and the amount of nicotine intake is the same. Additionally, the associations between the mediators in the present study and health status might be further mediated by additional factors, such as stress, health risk behaviors, and mistrust in the health system (Pascoe \& Smart Richman, 2009; Williams \& Mohammed, 2009). We strongly encourage researchers to explicitly examine mechanisms at different levels (e.g., societal, interpersonal, intrapersonal, physiological, and genetic/epigenetic) in order to develop a more comprehensive conceptual model that addresses the association between skin tone, health 
risk behaviors, and health outcomes. In doing so, health outcomes should be assessed with multiple measures that capture both global health functioning as well as the presence/absence of specific diseases.

\section{Conclusion}

Understanding mechanisms underlying the association between skin tone and health in Blacks is crucial for developing effective interventions designed to reduce the negative health consequences of not only category-based discrimination but also feature-based discrimination. Our findings suggest self-esteem plays a particularly essential role in mediating the skin tonehealth link. The present study highlights the important role feature-based discrimination plays, above and beyond category-based discrimination, in determining mental and physical health outcomes among Blacks. 


\section{References}

Abramson, Corey M, Manata Hashemi, and Martín Sánchez-Jankowski. 2015. "Perceived

Discrimination in U.S. Healthcare: Charting the Effects of Key Social Characteristics within and across Racial Groups.” Preventive Medicine Reports 2. Elsevier B.V.: 615-21. doi:10.1016/j.pmedr.2015.07.006.

Allen, Walter, Edward Telles, and Margaret Hunter. 2000. "Skin Color, Income and Education: A Comparison of African Americans and Mexican Americans.” National Journal of Sociology 12 (1): 129-80.

http://search.ebscohost.com/login.aspx?direct=true\&db=sih\&AN=19751697\&site=ehostlive.

Altschuler, Andrea, Carol P. Somkin, and Nancy E. Adler. 2004. "Local Services and Amenities, Neighborhood Social Capital, and Health.” Social Science and Medicine 59 (6): 1219-29. doi:10.1016/j.socscimed.2004.01.008.

Antonucci, T C, J F Peggs, and J T Marquez. 1989. “The Relationship between Self-Esteem and Physical Health in a Family Practice Population.” Family Practice Research Journal 9 (1): $65-72$.

Armstead, C. a., J. R. Hebert, E. K. Griffin, and G. M. Prince. 2013. “A Question of Color: The Influence of Skin Color and Stress on Resting Blood Pressure and Body Mass Among African American Women.” Journal of Black Psychology 40 (5): 424-50. doi: $10.1177 / 0095798413494404$.

Barrett, Paula M, Hayley M Webster, and Jeffrey R Wallis. 1999. “Adolescent Self-Esteem and Cognitive Skills Training: A School-Based Intervention.” Journal of Child and Family Studies 8 (2): 217-27. doi:10.1023/A:1022044119273. 
Becker, Gay, and Edwina Newsom. 2003. "Socioeconomic Status and Dissatisfaction with Health Care among Chronically Ill African Americans." American Journal of Public Health. doi:10.2105/AJPH.93.5.742.

Belgrave, Faye Z, Gretchen Chase-Vaughn, Famebridge Gray, Jerveada Dixon Addison, and Valerie R Cherry Tampa. 2000. “The Effectiveness of a Culture-and Gender-Specific Intervention for Increasing Resiliency Among African American Preadolescent Females.” Journal of Black Psychology Preadolescent Females Journal of Black Psychology 26 (2): 133-47. doi:10.1177/0095798400026002001.

Bennett, Gary G., Kathleen Yaus Wolin, Elwood L. Robinson, Sherrye Fowler, and Christopher L. Edwards. 2005. "Perceived Racial/ethnic Harassment and Tobacco Use among African American Young Adults." American Journal of Public Health 95 (2): 238-40. doi:10.2105/AJPH.2004.037812.

Blair, Irene V, Charles M Judd, Melody S Sadler, and Christopher Jenkins. 2002. "The Role of Afrocentric Features in Person Perception: Judging by Features and Categories.” Journal of Personality and Social Psychology 83 (1): 5-25. doi:10.1037/0022-3514.83.1.5.

Borrell, Luisa N., David R. Jacobs, David R. Williams, Mark J. Pletcher, Thomas K. Houston, and Catarina I. Kiefe. 2007. "Self-Reported Racial Discrimination and Substance Use in the Coronary Artery Risk Development in Adults Study.” American Journal of Epidemiology 166 (9): 1068-79. doi:10.1093/aje/kwm180.

Borrell, Luisa N., Catarina I. Kiefe, David R. Williams, Ana V. Diez-Roux, and Penny GordonLarsen. 2006. "Self-Reported Health, Perceived Racial Discrimination, and Skin Color in African Americans in the CARDIA Study." Social Science and Medicine 63 (6): 1415-27. doi:10.1016/j.socscimed.2006.04.008. 
Branigan, Amelia R., Jeremy Freese, Assaf Patir, Thomas W. McDade, Kiang Liu, and Catarina I. Kiefe. 2013. "Skin Color, Sex, and Educational Attainment in the Post-Civil Rights Era." Social Science Research 42 (6). Elsevier Inc.: 1659-74.

doi:10.1016/j.ssresearch.2013.07.010.

Branscombe, Nyla R., Michael T. Schmitt, and Richard D. Harvey. 1999. "Perceiving Pervasive Discrimination among African Americans: Implications for Group Identification and WellBeing.” Journal of Personality and Social Psychology 77 (1): 135-49. doi:10.1037/00223514.77.1.135.

Brewer, M B. 1988. “A Dual Process Model of Impression Formation.” In Advances in Social Cognition, Vol 1, 1-36.

Bristow, Robert E., Matthew A. Powell, Noor Al-Hammadi, Ling Chen, J. Philip Miller, Phillip Y. Roland, David G. Mutch, and William A. Cliby. 2013. "Disparities in Ovarian Cancer Care Quality and Survival according to Race and Socioeconomic Status." Journal of the National Cancer Institute 105 (11): 823-32. doi:10.1093/jnci/djt065.

Brody, Gene H, Man-Kit Lei, David H Chae, Tianyi Yu, Steven M Kogan, and Steven R H Beach. 2014. "Perceived Discrimination among African American Adolescents and Allostatic Load: A Longitudinal Analysis with Buffering Effects.” Child Development 85 (3): 989-1002. doi:10.1111/cdev.12213.

Carroll, James L, and Melissa Buhrow. 1994. "Concurrent Validity of the Culture-Free SelfEsteem Inventory and Physical Health in College Students.” Psychological Reports 74: 553-54. doi:10.2466/pr0.1994.74.2.553.

Castor, Mei L, Michael S Smyser, Maile M Taualii, Alice N Park, Shelley A Lawson, and Ralph A Forquera. 2006. "A Nationwide Population-Based Study Identifying Health Disparities 
between American Indians/Alaska Natives and the General Populations Living in Select Urban Counties.” American Journal of Public Health 96 (8). United States: 1478-84. doi:10.2105/AJPH.2004.053942.

Cerin, Ester, and David P MacKinnon. 2009. "A Commentary on Current Practice in Mediating Variable Analyses in Behavioural Nutrition and Physical Activity." Public Health Nutrition 12 (8): 1182-88. doi:10.1017/S1368980008003649.

Chan, Ivy W. S., Julian C. L. Lai, and Kris W. N. Wong. 2006. "Resilience Is Associated with Better Recovery in Chinese People Diagnosed with Coronary Heart Disease." Psychology \& Health 21 (June): 335-49. doi:10.1080/14768320500215137.

Coard, Stephanie, Breland Breland, and Patricia Raskin. 2001. "Perceptions of and Preferences for Skin Color, Black Racial Identity, and Self-Esteem among African Americans.”Journal of Applied Social Psychology 31 (11): 2256-74. doi:10.1111/j.1559-1816.2001.tb00174.x.

Cohen, Geoffrey L, and David K Sherman. 2014. "The Psychology of Change: Self-Affirmation and Social Psychological Intervention.” Annual Review of Psychology 65: 333-71. doi:10.1146/annurev-psych-010213-115137.

Cooper, D C, P J Mills, W A Bardwell, M G Ziegler, and J E Dimsdale. 2009. “The Effects of Ethnic Discrimination and Socioeconomic Status on Endothelin-1 among Blacks and Whites." Am J Hypertens 22 (7): 698-704. doi:10.1038/ajh.2009.72.

Corning, Alexandra F. 2002. "Self-Esteem as a Moderator between Perceived Discrimination and Psychological Distress among Women.” Journal of Counseling Psychology 49 (1): 117-26. doi:10.1037/0022-0167.49.1.117.

Daniel, James Z., Matthew Hickman, John Macleod, Nicola Wiles, Anne Lingford-Hughes, Michael Farrell, Ricardo Araya, Petros Skapinakis, Jon Haynes, and Glyn Lewis. 2009. "Is 
Socioeconomic Status in Early Life Associated with Drug Use? A Systematic Review of the Evidence." Drug and Alcohol Review 28 (2): 142-53. doi:10.1111/j.14653362.2008.00042.x.

Danielson, Carla Kmett, Kate Walsh, Jenna McCauley, Kenneth J Ruggiero, Jennifer L Brown, Jessica M Sales, Eve Rose, Gina M Wingood, and Ralph J DiClemente. 2014. “HIVRelated Sexual Risk Behavior Among African American Adolescent Girls." Journal of Women's Health (15409996) 23 (5). Department of Epidemiology, Columbia University, New York, New York.: Mary Ann Liebert, Inc.: 413-19. doi:10.1089/jwh.2013.4599. Day-Vines, Norma L, and Veronica Terriquez. 2008. “A Strengths-Based Approach to Promoting Prosocial Behavior among African American and Latino Students.” Special Issue: Strengths-Based School Counseling 12 (2): 170-75. http://ovidsp.ovid.com/ovidweb.cgi?T $=\mathrm{JS} \& \mathrm{PAGE}=$ reference $\& \mathrm{D}=\mathrm{psyc} 6 \& \mathrm{NEWS}=\mathrm{N} \& \mathrm{AN}=$ 2008-18573-019.

Dressler, W. W. 1991. "Social Class, Skin Color, and Arterial Blood Pressure in Two Societies." Ethnicity \& Disease 1 (1): 60-77.

Duru, OK, NT Harawa, D Kermah, and KC Norris. 2012. “Allostatic Load Burden and Racial Disparities in Mortality." Journal of the National Medical Association 104 (1-2). Elsevier Masson SAS: 89-95. doi:10.1016/S0027-9684(15)30120-6.

Fein, Steven, and Steven J Spencer. 1997. "Prejudice as Self-Image Maintenance: Affirming the Self through Derogating Others.” Journal of Personality and Social Psychology 73 (1). American Psychological Association: 31.

Feng, Danjun, and Lingzhong Xu. 2015. “The Relationship between Perceived Discrimination and Psychological Distress among Chinese Pulmonary Tuberculosis Patients: The 
Moderating Role of Self-Esteem." Psychology, Health \& Medicine 20 (2). Routledge: 17785. doi:10.1080/13548506.2014.958505.

Franks, Peter, Marthe R Gold, and Kevin Fiscella. 2003. "Sociodemographics, Self-Rated Health, and Mortality in the US.” Social Science \& Medicine 56 (12): 2505-14. doi:10.1016/S0277-9536(02)00281-2.

Ghee, Kenneth L., Jim Walker, and Anna Cash Younger. 1998. "The RAAMUS Academy." Journal of Prevention \& Intervention in the Community 16 (1-2): 87-102. doi:10.1300/ J005v16n01_05.

Gruenewald, Tara L., Arun S. Karlamangla, Perry Hu, Sharon Stein-Merkin, Carolyn Crandall, Brandon Koretz, and Teresa E. Seeman. 2012. "History of Socioeconomic Disadvantage and Allostatic Load in Later Life." Social Science and Medicine 74 (1): 75-83. doi:10.1016/j.socscimed.2011.09.037.

Gullette, Donna L., and Margaret A. Lyons. 2006. "Sensation Seeking, Self-Esteem, and Unprotected Sex in College Students." Journal of the Association of Nurses in AIDS Care 17 (5): 23-31. doi:10.1016/j.jana.2006.07.001.

Hamilton, Darrick, Arthur H. Goldsmith, and William Darity. 2009. "Shedding 'light' on Marriage: The Influence of Skin Shade on Marriage for Black Females.” Journal of Economic Behavior and Organization 72 (1): 30-50. doi:10.1016/j.jebo.2009.05.024.

Harburg, E., L. Gleibermann, P. Roeper, M. A. Schork, and W. J. Schull. 1978. "Skin Color, Ethnicity, and Blood Pressure. I. Detroit Blacks.” American Journal of Public Health 68 (12): 1177-83. doi:10.2105/AJPH.68.12.1177.

Harris, Mathew A, Caroline E Brett, John M Starr, Ian J Deary, and Andrew M McIntosh. 2016. "Early-Life Predictors of Resilience and Related Outcomes up to 66 Years Later in the 6- 
Day Sample of the 1947 Scottish Mental Survey." Social Psychiatry and Psychiatric Epidemiology 51 (5). Germany: 659-68. doi:10.1007/s00127-016-1189-4.

Harvey, R D, N LaBeach, E Pridgen, and T M Gocial. 2005. “The Intragroup Stigmatization of Skin Tone among Black Americans.” Journal of Black Psychology 31: 237-53.

Hayes, A. F. 2013. Introduction to Meditaion, Moderation, and Conditional Process Analysis: A Regression-Based Approach. Guilford Press. doi:10.5539/ass.v11n9p207.

Hayes, Andrew F. 2009. "Beyond Baron and Kenny: Statistical Mediation Analysis in the New Millennium." Communication Monographs 76 (4). Routledge: 408-20. doi:10.1080/03637750903310360.

Hayman, Lenwood W, Todd Lucas, and John H Porcerelli. 2014. “Cognitive Appraisal vs. Exposure-Based Stress Measures: Links to Perceived Mental and Physical Health in LowIncome Black Women.” The Journal of Nervous and Mental Disease 202 (11): 807-12. doi:10.1097/NMD.0000000000000198.

Hughes, Michael, and Bradley I L Hertel. 1990. "The Significance of Color Remains : A Study of Life Chances , Mate Slection, and Ethnic Consciousness Among Black Americans *." Social Forces. doi:10.2307/2579136.

Hunter, Margaret L. 2007. “The Persistent Problem of Colorism: Skin Tone, Status, and Inequality." Sociology Compass 1 (1): 237-54. doi:10.1111/j.1751-9020.2007.00006.x.

Jackson, James S, Darrell Hudson, Kiarri Kershaw, Briana Mezuk, Jane Rafferty, and Katherine Knight Tuttle. 2011. "Discrimination, Chronic Stress, and Mortality Among Black Americans: A Life Course Framework.” In International Handbook of Adult Mortality, edited by Richard G Rogers and Eileen M Crimmins, 311-28. Dordrecht: Springer Netherlands. doi:10.1007/978-90-481-9996-9_15. 
Keil, J E, S H Sandifer, C B Loadholt, and E Boyle Jr. 1981. "Skin Color and Education Effects on Blood Pressure.” Am J Public Health 71 (5): 532-34.

Keith, Verna M., and Cedric Herring. 1991. "Skin Tone and Stratification in the Black Community." American Journal of Sociology 97 (3): 760. doi:10.1086/229819.

Keith, Verna M., Karen D. Lincoln, Robert Joseph Taylor, and James S. Jackson. 2010. "Discriminatory Experiences and Depressive Symptoms among African American Women: Do Skin Tone and Mastery Matter?” Sex Roles 62 (1): 48-59. doi:10.1007/s11199-0099706-5.

Kling, Kristen C, Janet Shibley Hyde, Carolin J Showers, and Brenda N Buswell. 1999. “Gender Differences in Self-Esteem: A Meta-Analysis.” Psychological Bulletin. US: American Psychological Association. doi:10.1037/0033-2909.125.4.470.

Klonoff, Elizabeth A., and Hope Landrine. 2000. "Is Skin Color a Marker for Racial Discrimination? Explaining the Skin Color-Hypertension Relationship." Journal of Behavioral Medicine 23 (4): 329-38. doi:10.1023/A:1005580300128.

Krieger, N, S Sidney, and E Coakley. 1998. "Racial Discrimination and Skin Color in the CARDIA Study: Implications for Public Health Research.” American Journal of Public Health 88 (9): 1308-13.

Levin, Shana, Stacey Sinclair, Rosemary C Veniegas, and Pamela L Taylor. 2002. "Perceived Discrimination in the Context of Multiple Group Memberships." Psychological Science : A Journal of the American Psychological Society / APS 13 (6): 557-60. doi:10.1111/14679280.00498.

Lipowicz, Anna, Alicja Szklarska, and Robert M Malina. 2014. “Allostatic Load and Socioeconomic Status in Polish Adult Men.” Journal of Biosocial Science 46 (2): 155-67. 
doi:10.1017/S0021932013000345.

Livingston, R W, and M B Brewer. 2002. "What Are We Really Priming? Cue-Based versus Category-Based Processing of Facial Stimuli.” Journal of Personality and Social Psychology 82: 5-18.

Martin, Jack K, Steven A. Tuch, and Paul M. Roman. 2003. "Problem Drinking Patterns among African Americans : The Impacts of Reports of Discrimination, Perceptions of Prejudice, and 'Risky' Coping Strategies Author ( S ): Jack K. Martin, Steven A. Tuch and Paul M . Roman Source : Journal of Health and Soc." Journal of Health and Social Behavior 44 (3): $408-25$.

Massey, Douglas S. 2004. "SEGREGATION AND STRATIFICATION: A Biosocial Perspective STATE OF THE DISCIPLINE SEGREGATION AND STRATIFICATION A Biosocial Perspective.” Du Bois Review 11 (1). Thompkins-McCaw Library: 7-25. doi:10.1017/S1742058X04040032.

Mays, Vickie M, Susan D Cochran, and Namdi W Barnes. 2007. "Race, Race-Based Discrimination, and Health Outcomes Among African Americans." Annual Review of Psychology 58: 201-25. doi:10.1146/annurev.psych.57.102904.190212.

Monk, Ellis P. 2015. "The Cost of Color : Skin Color, Discrimination, and Health among African-Americans.” American Journal of Sociology 121 (2): 396-444. doi:http://doi.org/10.1086/682162.

Mruk, Christopher J J. 2006. Self-Esteem Research, Theory, and Practice: Toward a Positive Psychology of Self-Esteem. Springer Publishing Company.

Okeke-Adeyanju, Ndidi, Lorraine C Taylor, Ashley B Craig, Rachel E Smith, Aqiyla Thomas, Alaina E Boyle, and Melissa E DeRosier. 2014. "Celebrating the Strengths of Black Youth: 
Increasing Self-Esteem and Implications for Prevention.” JOURNAL OF PRIMARY

PREVENTION 35 (5). 233 SPRING ST, NEW YORK, NY 10013 USA: SPRINGER: 35769. doi:10.1007/s10935-014-0356-1.

Orth, Ulrich, Richard W Robins, and Keith F Widaman. 2012. "Life-Span Development of SelfEsteem and Its Effects on Important Life Outcomes." Journal of Personality and Social Psychology. Orth, Ulrich: Department of Psychology, University of Basel, Missionsstrasse 62, Basal, Switzerland, 4055, ulrich.orth@unibas.ch: American Psychological Association. doi:10.1037/a0025558.

Pascoe, Elizabeth A, and Laura Smart Richman. 2009. "Perceived Discrimination and Health: A Meta-Analytic Review.” Psychological Bulletin 135 (4): 531-54. doi:10.1037/a0016059.Perceived.

Pershing, Lynn K, Vidyanath P Tirumala, Joel L Nelson, Judy L Corlett, Anne G Lin, Laurence J Meyer, and Sancy a Leachman. 2008. "Reflectance Spectrophotometer: The Dermatologists' Sphygmomanometer for Skin Phototyping?” The Journal of Investigative Dermatology 128 (7): 1633-40. doi:10.1038/sj.jid.5701238.

Quon, Elizabeth C, and Jennifer J McGrath. 2015. "Community, Family, and Subjective Socioeconomic Status: Relative Status and Adolescent Health.” Health Psychology 34 (6): 591-601. doi:10.1037/hea0000135.

Richman, Laura Smart, and Charles Jonassaint. 2008. "The Effects of Race-Related Stress on Cortisol Reactivity in the Laboratory: Implications of the Duke Lacrosse Scandal.” Annals of Behavioral Medicine : A Publication of the Society of Behavioral Medicine 35 (1). NIH Public Access: 105-10. doi:10.1007/s12160-007-9013-8.

Rosenberg, M. 1965. "Rosenberg Self-Esteem Scale.” New York, ? doi:/S0034- 
98872009000600009.

Saperstein, Aliya, and Andrew M. Penner. 2010. "The Race of a Criminal Record: How Incarceration Colors Racial Perceptions.” Social Problems 57 (1): 92-113. doi:10.1525/sp.2010.57.1.92.

Saperstein, Aliya. 2012. "Racial Fluidity and Inequality in the United States." American Journal of Sociology 118 (3): 676-727.doi:10.1163/_afco_asc_2291.

Sprecher, Susan, James E. Brooks, and Winfred Avogo. 2013. "Self-Esteem Among Young Adults: Differences and Similarities Based on Gender, Race, and Cohort (1990-2012).” Sex Roles 69 (5-6): 264-75. doi:10.1007/s11199-013-0295-y.

Sweet, Elizabeth, Thomas W. McDade, Catarina I. Kiefe, and Kiang Liu. 2007. "Relationships between Skin Color, Income, and Blood Pressure among African Americans in the CARDIA Study." American Journal of Public Health 97 (12): 2253-59. doi:10.2105/AJPH.2006.088799.

Tesser, Abraham. 2000. “On Confluence of Self-Esteem Maintance Mechanisms.” Personality and Social Psychology Review 4 (4): 290-99.

Tirlea, Loredana, Helen Truby, and Terry P. Haines. 2016. "Pragmatic, Randomized Controlled Trials of the Girls on the Go! Program to Improve Self-Esteem in Girls.” American Journal of Health Promotion 30 (4): 231-41. doi:10.1177/0890117116639572.

Tomfohr, Lianne M, Meredith A Pung, and Joel E Dimsdale. 2016. "Mediators of the Relationship between Race and Allostatic Load in African and White Americans." Health Psychology. Tomfohr, Lianne M.: Department of Psychology, University of Calgary, University Drive Northwest, Calgary, AB, Canada, T2N 1N4, ltomfohr@ucalgary.ca: American Psychological Association. doi:10.1037/hea0000251. 
Tremblay, M. S., J Wyatt Inman, and J Douglas Willms. 2000. "The Relationship Between Physical Activity, Self-Esteem , and Academic Achievement in 12-Year-Old Children.” Pediatric Exercise Science 12 (3): 312-23.

Tucker, Carolyn M, and Keith C Herman. 2002. "Using Culturally Sensitive Theories and Research to Meet the Academic Needs of Low-Income African American Children." The American Psychologist 57 (10): 762-73. doi:10.1037/0003-066X.57.10.762.

U.S Bureaus of Census \& Labor Statistics. 2010. "Current Population Survey” 1: 14-20. http://www.bls.gov/cps/tables.htm.

Umaña-Taylor, Adriana J., Delfino Vargas-Chanes, Cristal D. Garcia, and Melinda GonzalesBacken. 2008. “A Longitudinal Examination of Latino Adolescents’ Ethnic Identity, Coping With Discrimination, and Self-Esteem.” The Journal of Early Adolescence 28 (1): 16-50. doi:10.1177/0272431607308666.

Upchurch, Dawn M., Judith Stein, Gail a. Greendale, Laura Chyu, Chi-Hong Tseng, Mei-Hua Huang, Tené T. Lewis, Howard M. Kravitz, and Teresa Seeman. 2015. “A Longitudinal Investigation of Race, Socioeconomic Status, and Psychosocial Mediators of Allostatic Load in Midlife Women.” Psychosomatic Medicine 77 (May): 402-12. doi:10.1097/PSY.0000000000000175.

Uzogara, Ekeoma E., Hedwig Lee, Cleopatra M. Abdou, and James S. Jackson. 2013. “A Comparison of Skin Tone Discrimination among African American Men: 1995 and 2003.” Psychology of Men \& Masculinity 15 (2): 201-12. doi:10.1037/a0033479.

Ware Jr., J E, M Kosinski, J E Dewey, and B Gandek. 2001. How to Scoreand Interpret SingleItem Health Status Measures: AManual For Users of the SF-8 Health Survey. Lincoln(RI): QualityMetric Incorporated. 
Wei, Meifen, Tsun-Yao Ku, Daniel W Russell, Kelly Yu-Hsin Liao, and Brent Mallinckrodt. 2008. "Moderating Effects of Three Coping Strategies and Self-Esteem on Perceived Discrimination and Depressive Symptoms: A Minority Stress Model for Asian International Students.” Journal of Counseling Psychology 55 (4): 451-62. doi:10.1037/a0012511.

Williams, David R., and Selina A. Mohammed. 2009. "Discrimination and Racial Disparities in Health: Evidence and Needed Research.” Journal of Behavioral Medicine 32 (1): 20-47. doi:10.1007/s10865-008-9185-0.

Williams, D, and R Williams-Morris. 2000. "Racism and Mental Health: The African American Experience.” Ethnicity \& Health 5 (3-4): 243-68. doi:10.1080/713667453.

Yi, Joyce P, Peter P Vitaliano, Ronald E Smith, Jean C Yi, and Katie Weinger. 2008. “The Role of Resilience on Psychological Adjustment and Physical Health in Patients with Diabetes.” British Journal of Health Psychology 13 (Pt 2): 311-25. doi:10.1348/135910707X186994. 
Table 1. Participant basic demographic characteristics

Characteristics

$M(S D)$ or $N(\%)$

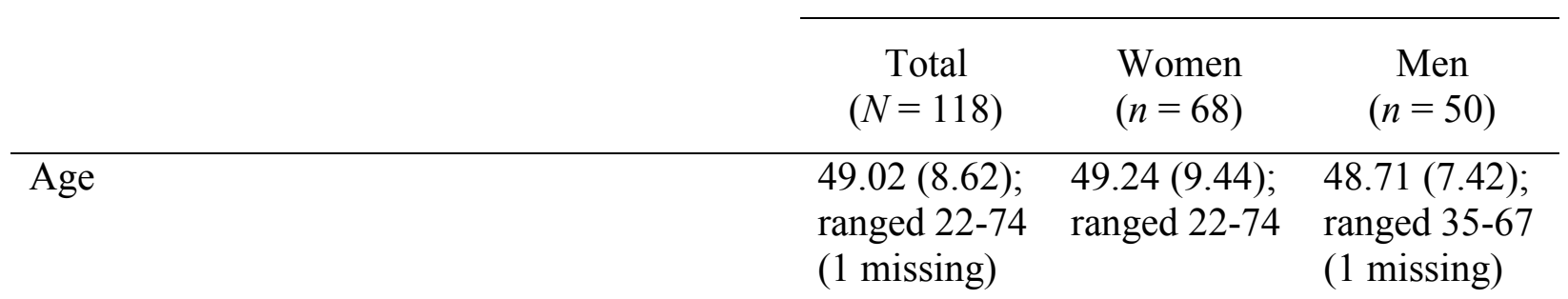

Education

Completed $8^{\text {th }}$ grade or less $\quad(z=-1.92) \quad 5(4.2 \%) \quad 3(4.4 \%) \quad 2(4.0 \%)$

Completed $10^{\text {th }}$ grade or less $\quad(z=-1.32) \quad 19(16.1 \%) \quad 7(10.3 \%) \quad 12(24.0 \%)$

Completed $12^{\text {th }}$ grade or less $\quad(z=-.72) \quad 17(14.4 \%) \quad 5(7.4 \%) \quad 12(24.0 \%)$

Graduated from high school $\quad(z=-.12) \quad 18(15.3 \%) \quad 10(14.7 \%) \quad 8(16.0 \%)$

Completed some college $\quad(z=.47) \quad 29(24.6 \%) \quad 19(27.9 \%) \quad 10(20.0 \%)$

Graduated from college $\quad(z=.07) \quad 20(16.9 \%) \quad 14(20.6 \%) \quad 6(12.0 \%)$

Completed post-graduate degree $(z=1.67) \quad 10(8.5 \%) \quad 10(14.7 \%) \quad 0(0.0 \%)$

Income

$\begin{array}{lllll}\text { Less than } \$ 20,000 & (z=-.91) & 50(42.4 \%) & 27(39.7 \%) & 23(46.0 \%) \\ \$ 20,000 \text { to } \$ 39,999 & (z=-.09) & 25(21.2 \%) & 14(20.6 \%) & 11(22.0 \%) \\ \$ 40,000 \text { to } \$ 59,999 & (z=.72) & 27(22.9 \%) & 16(23.5 \%) & 11(22.0 \%) \\ \$ 60,000 \text { to } \$ 89,999 & (z=1.54) & 8(6.8 \%) & 5(7.4 \%) & 3(6.0 \%) \\ \text { More than } \$ 90,000 & (z=2.36) & 8(6.8 \%) & 6(8.8 \%) & 2(4.0 \%)\end{array}$


Table 2. Means, SD, and partial correlations among all variables while controlling for age

\begin{tabular}{|c|c|c|c|c|c|c|c|}
\hline & & 1 & 2 & 3 & 4 & 5 & 6 \\
\hline 1. Skin Tone & & - & $.16^{\dagger}$ & $.19^{*}$ & $-.23^{*}$ & $.36^{* *}$ & $.25^{* *}$ \\
\hline 2. Self-reported Physical Health & & & - & $.66^{* *}$ & -.003 & $.26^{* *}$ & $.45^{* *}$ \\
\hline 3. Self-reported Mental Health & & & & - & $-.20^{*}$ & $.20^{*}$ & $.43^{* *}$ \\
\hline 4. Perceived Discrimination & & & & & - & -.02 & -.05 \\
\hline 5. Socioeconomic status (SES) & & & & & & - & $.29^{* *}$ \\
\hline \multirow[t]{3}{*}{ 6. Self-Esteem } & & & & & & & - \\
\hline & $M$ & 40.61 & 70.30 & 68.91 & 3.18 & .00 & 4.08 \\
\hline & $S D$ & 6.25 & 21.72 & 21.11 & .96 & .83 & .63 \\
\hline
\end{tabular}

Note. $\dagger$ indicates $p<.10, *$ indicates $p<.05$, and $* *$ indicates $p<.01$. 
Figure 1. Mediation analysis predicting participants' self-reported physical and mental health with age as a covariate

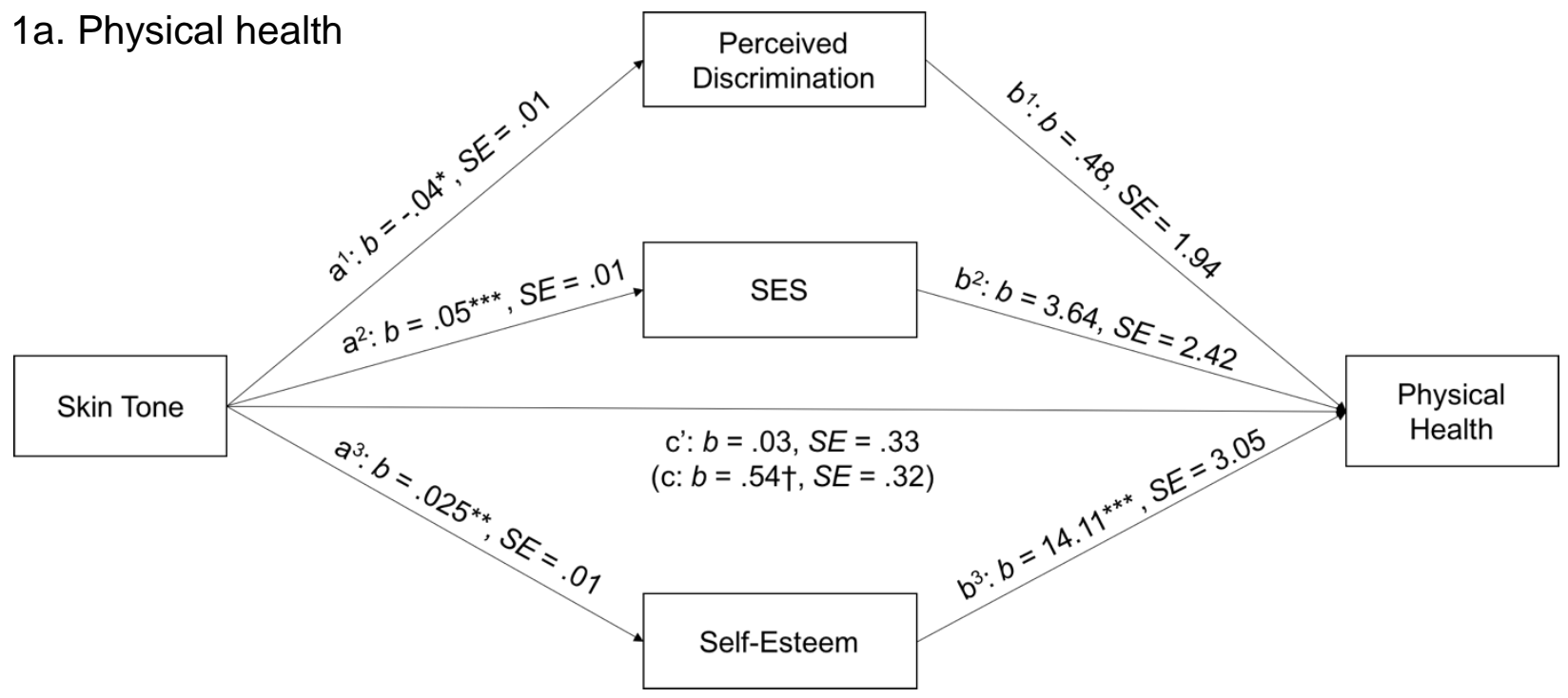

The Sobel test for the $a^{3 *} b^{3}$ path is $Z=2.31, p<.05$. Confidence interval computed using a bootstrap method for the $\mathrm{a}^{3 *} \mathrm{~b}^{3}$ path $=.10$ to .74 .

1b. Mental health

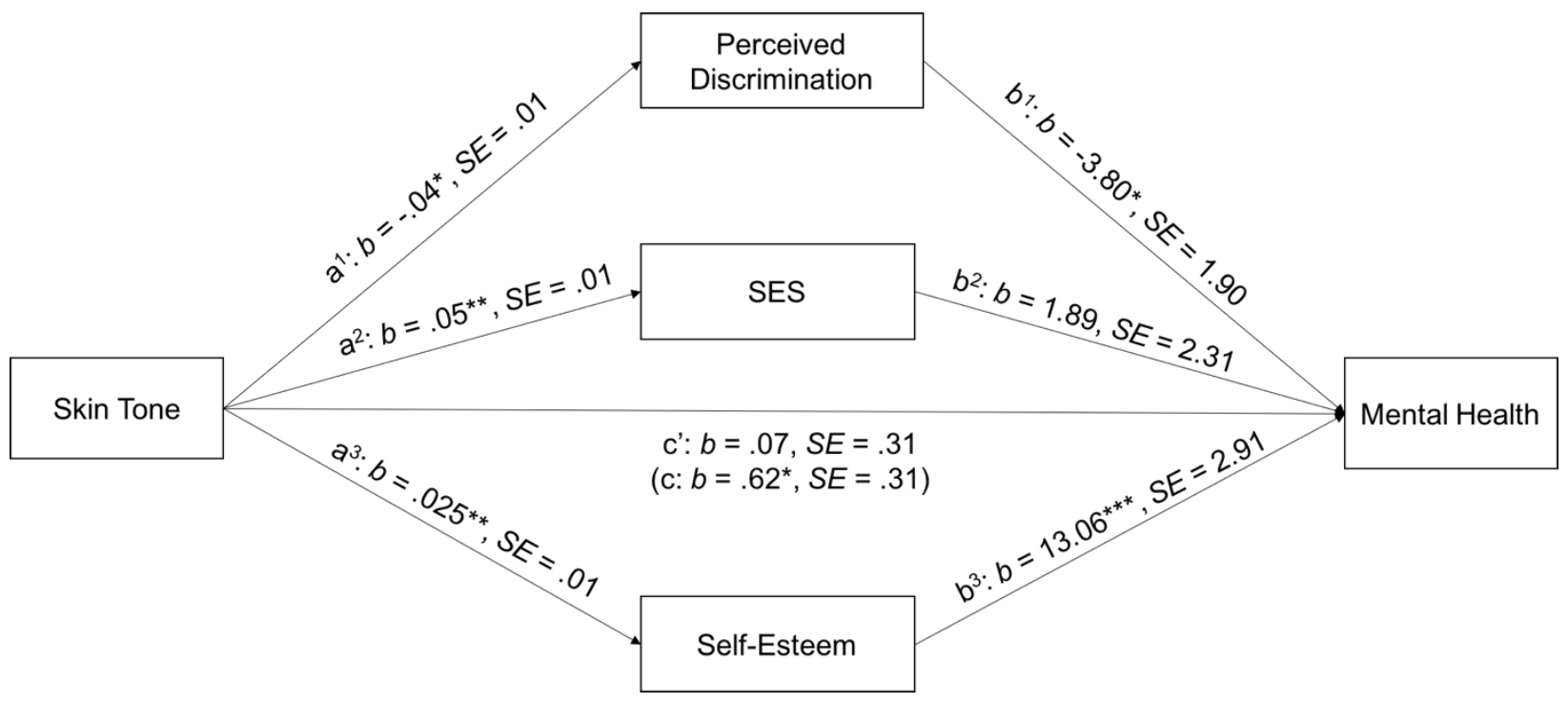

The Sobel test for the $\mathrm{a}^{3 *} \mathrm{~b}^{3}$ path is $Z=2.29, p<.05$. Confidence interval computed using a bootstrap method for the $\mathrm{a}^{3 *} \mathrm{~b}^{3}$ path $=.10$ to .68 .

Note. $\dagger$ indicates $p<.10, *$ indicates $p<.05, * *$ indicates $p<.01, * * *$ indicates $p<.001$. 